\title{
Partilhar e multiplicar histórias de fato: a narração do acontecimento na mídia
}

Ivan Paganotti

\section{Resumo:}

Resenha do livro A narração do fato: notas para uma teoria do acontecimento.

\section{Palavras Chave:}

Muniz Sodré, jornalismo, narrativa.

\section{Abstract:}

Book review A narração do fato: notas para uma teoria do acontecimento.

\section{Keywords:}

Muniz Sodré, journalism, narrative.

\section{SODRÉ, Muniz. A narração do fato: notas para uma teoria do acontecimento. Petrópolis: Vozes, 2009, 288pp.}

Uma bomba explode. Pode ser no Iraque, no Afeganistão ou em qualquer outro vizinho do Oriente Médio com uma estabilidade política de nitroglicerina. Pode ser uma bomba israelense na Palestina, ou um homem-bomba palestino em Israel. Ou uma explosão no Chifre da África, no Haiti, na periferia de Paris, no centro do Rio de Janeiro...

Outra bomba explode. Podia ser a mesma.

Sem as histórias por trás das vidas perdidas, sem as causas e consequências dos eventos, a bomba explode em silêncio, o mundo não ouve ou cala. São somente dados, estatísticas de violência que se avolumam entre a oscilação nas cotações de moedas estrangeiras e os quilômetros de congestionamento nas estradas durante o feriado.

Para além desses dados crus, de difícil digestão, o jornalismo se omite no seu papel de relatar mais do que fatos: é preciso mostrar os significados sociais do que aconteceu. Clamando por transparência, o jornalismo joga fora o sentido dos acontecimentos que reporta ao se recusar a tecer os fios das histórias que conectam os fatos.

Para analisar o porquê da perda de sentido decorrente das estruturas narrativas insípidas que se tornaram modelo de "bom jornalismo", é preciso reconstruir a relação entre as notícias e suas histórias. No livro $A$ narração do fato: notas para uma teoria do acontecimento, Muniz Sodré tenta reconstruir os valores que levaram o jornalismo a padronizar as formas de contar histórias, e sinaliza caminhos para reatar os pontos entre a boa informação e a narrativa envolvente. 


\section{Enredar os fatos e envolver o público}

"Reportar", lembra Sodré, tem sua origem etimológica no latim "reportare", que significa "levar alguém" (para o jornalismo, o seu público) à cena dos acontecimentos (SODRÉ, 2009: 171). O jornalista age assim como um representante do olhar do seu público; vai aonde poucos teriam acesso e conta as histórias que muitos preferiam que não fossem ouvidas. Como um mediador, constrói uma narrativa que entrelaça os fatos ao mesmo tempo em que envolve seu público, e amarra seu tema e seus leitores em um único enredo. A analogia empregada por Sodré é bastante rica, nesse sentido: enquanto a notícia funciona como um retrato, uma foto $3 \times 4$ dos acontecimentos, a reportagem coloca em movimento essas imagens e envolve seu leitor da mesma forma como o cinema cria a ilusão de movimento pela sequência de quadros. O fluxo narrativo construído pela reportagem enreda os fatos e envolve o leitor, interessado pelo desenrolar da história tanto quanto pela pertinência do tema por se sentir transportado para o meio das cenas dos acontecimentos, como num filme. Talvez seja por isso que, como Sodré aponta, muitas das estratégias do chamado "Novo Jornalismo" adotam influências não só da literatura, mas também de suportes audiovisuais, para contar suas histórias.

A possibilidade de envolver o público nos meandros dos eventos reportados leva Sodré a uma das suas definições mais abrangentes. No primeiro capítulo do livro, "O discurso do acontecimento", o autor conceitua notícia como o relato de algo que foi ou será inscrito na trama de relações cotidianas (Idem, Ibidem: 24). O mesmo capítulo apresenta outra definição mais restrita, ao apresentar a notícia como uma micro-narrativa de um acontecimento factual, inscrito na realidade histórica e, portanto, passível de comprovação (Idem, Ibidem: 71). No primeiro sentido dialógico, é uma construção textual que se ampara em outros textos anteriores e será re-significada após sua recepção pelo público - ou seja, é pautada por eventos anteriores, nos quais se inspira, e pauta o debate público, que pretende influenciar. Como muitos outros textos ficcionais também podem ter esse mesmo efeito, é importante complementar a primeira generalização com a segunda restrição, que determina que o relato seja baseado em fatos, ou seja, eventos inseridos na "realidade", comprovados pela citação de fontes.

Além de ancorar-se em fontes fidedignas, a própria linguagem jornalística busca a objetividade em construções impessoais, ocultando marcas de subjetividade e com a suposta separação de informações e opiniões - cânones do jornalismo contemporâneo analisados por Sodré no primeiro capítulo do livro e que procuram garantir o valor de credibilidade e transparência para a mídia que os emprega.

Mas essa dieta narrativa de baixa subjetividade prejudicou a degustação de muitas reportagens por parte de um público de paladar ávido por histórias mais calóricas. No segundo capítulo, "A experiência narrativa", Sodré mostra os pontos de encontro e de divergência entre a literatura e o jornalismo, tanto pelas estratégias de construção narrativa quanto pelo valor simbólico atrelado pelo público para seus relatos. Assim, delineia algumas críticas e recomendações para que o jornalista volte a narrar de fato (e não só relatar) as notícias. O paralelo entre literatura e jornalismo é também retomado na terceira e última seção do livro, "O fato em vermelho-sangue", que apresenta um paralelo específico entre os romances policiais e as estratégias de investigação e narração do jornalismo por meio da revelação de informações desconhecidas e da construção de tensão e suspense nos relatos.

\section{Fatos marcantes}

Para compreender a narração dos acontecimentos, Sodré esquematiza o processo em que os fatos ganham sentido a partir da sua seleção e tratamento para transmissão. Para o autor, um "fato bruto" é transformado em acontecimento por meio de um processo de interpretação que procura os sentidos sociais dos eventos, ou seja, que busca algo digno de comunicação entre milhares de situações cotidianas. Ao identificar e divulgar os desvios e as rupturas no tecido social, o jornalismo "confirma a previsibilidade da 
ordem por meio da inscrição do ocorrido na causalidade do fato social" (Idem, Ibidem: 71). Assim, o acontecimento jornalístico trata-se de um "fato marcado, portanto, mais determinado para o sistema de informação pública do que outros existentes, tidos como não-marcados para a formação de um conhecimento sobre a cotidianidade" (Idem, Ibidem: 75). Essa "marca" relativa que o acontecimento carrega é o que diferencia o que tem valor de notícia do que não o tem; segundo Sodré, essa marcação é determinada pela possibilidade de instaurar uma narrativa a partir dos acontecimentos, o que significa que esse fato pode ser base para uma história de interesse. Com essa fórmula, Sodré retoma os "valoresnotícia" discutidos pelas teorias pragmáticas - e também vai além dessas teorias ao propor uma sistematização mais ampla de fatores como novidade, imprevisibilidade, peso social, proximidade, hierarquia dos envolvidos, magnitude, impacto e perspectivas de desdobramento dos fatos noticiados. A "marcação" que os eventos carregam supera fatores objetivos como esses valores da notícia, pois dependem do envolvimento - subjetivo, é importante frisar - do público com uma história narrada pelo jornalista a partir dos fatos.

Essa "marcação" que os eventos "noticiáveis" carregam também deixa outra "marca" nos modos como a sociedade se vê e representa seus eventos, pois apresenta modelos que pretendem controlar o aparecimento de fenômenos sociais. Esse controle é garantido pela domesticação e previsão dos fatos, "como se o fato de ontem fosse hoje noticiado para se saber o que se pode esperar do amanhã" (Idem, Ibidem: 98). Não se trata de manipulação ou sensacionalismo, dois dos frequentadores mais assíduos dos bancos dos réus da crítica midiática, mas da própria posição mediadora do jornalismo, que oscila entre o conhecimento sistematizado próximo do saber científico e o senso comum de seu público. Dessa forma, manipulação e sensacionalismo são sintomas - e não causas - das doenças que acometem o sistema informativo: se um veículo pende para a sistematização autoritária do saber a partir de um pólo iluminado, pode sofrer de uma infecção manipuladora; por outro lado, uma febre sensacionalista é resultado do apelo direto e sem crítica aos valores compartilhados por seu público.

Uma imprensa de qualidade, para Sodré, se ampara no tênue equilíbrio entre esses dois pólos: apresenta informações socialmente relevantes a partir de um ponto de vista próprio (independente do Estado ou de outros constrangimentos políticos ou econômicos), ao mesmo tempo em que é capar de influir na agenda pública pelo peso de seu público e de seu valor simbólico (Idem, Ibidem: 114). Mas Sodré alerta que é importante rever a pretensão de um espelhamento da verdade absoluta: admitir uma veracidade probabilística (no jornalismo, com o sentido de algo que pode ser provado) não destruirá o pacto de credibilidade entre os jornalistas e seu público (Idem, Ibidem: 135). Essa visão é fortalecida pelo argumento de que a imprensa não precisa apresentar Verdades filosóficas, mas uma "verdade pública" (Idem, Ibidem: 44), compromissada com a revelação de fatos que possam repercutir em efeitos sociais.

\section{Relatos transparentes ou insípidos?}

Para compreender o modelo narrativo das notícias, Sodré recupera formas arcaicas de relato como a construção mitológica a partir da narração de feitos exemplares. Apesar de uma aura racional, as narrativas jornalísticas atuais ainda amparam-se nessas estratégias, principalmente nos relatos de tragédias e conquistas individuais ou coletivas, assim como nos perfis de grandes personalidades ou de pequenas vidas anônimas. Transmitem-se histórias de vida para fixar na memória textual os relatos de comportamentos que podem ser tomados como modelo, inspiração - para as grandes celebridades ou para os heróis invisíveis do cotidiano - ou alvo de condenação - no caso de condutas reprováveis (Idem, Ibidem: 60). Ao demarcar os comportamentos louváveis ou desviantes, o jornalismo tenta fixar uma comunidade a partir dos modos de vida socialmente compartilhados, da mesma forma como os antigos narradores de mito que se reuniam ao redor das fogueiras ou na escuridão das cavernas. Agora, iluminados pelas telas dos aparelhos televisores ou pelos computadores, temos contato com relatos de todo o mundo num ritmo acelerado - mas qual o sentido que essas histórias adquiriram, com sua 
multiplicação?

Essa questão tenta ser resolvida por Sodré a partir da teoria sobre o (desaparecimento do) narrador discutida por Walter Benjamin (1). Sodré retoma a discussão sobre a diferença entre experiência (o conhecimento sistematizado obtido pela vida prática) e vivência (a revelação auferida do acontecimento a partir da experiência íntima do sujeito). O narrador benjaminiano funcionaria, na leitura de Sodré, como uma correia de transmissão do saber concreto - com conselhos e ensinamentos éticos ou práticos - para formar e manter a base comunicativa de um grupo social. Dessa forma, ao compartilhar um "divisor comum" com um grupo, garantem-se os valores fundamentais para o convívio e para o contato entre seus membros. Na metáfora de Sodré, constrói-se uma força centrípeta que atrai a diversidade do coletivo ao redor de símbolos centrais e unificadores por meio da narração de mitos fundacionais ou de destino, como lendas e sagas (Idem, Ibidem: 178). Assim, a transmissão da experiência humana que registra o passado molda também os comportamentos e visões do presente, ao mesmo tempo em que determina objetivos e planos futuros.

\section{Atar nós ao fio narrativo}

Levando a metáfora de Sodré ainda mais longe, essa força centrípeta é garantida pelos fios das histórias que unem, em nós, os indivíduos de um grupo, que passam a reconstruir novas histórias ao redor dos mesmos símbolos. Assim, a partir da ampliação dos "divisores comuns" de um grupo, passa-se também a permitir uma "multiplicação" de novos relatos sobre o que foi narrado: a notícia se apóia nas visões socialmente compartilhadas e (as) repercute nos comentários do seu público sobre os eventos que retrata.

Mas isso só é possível se retomarmos o sentido amplo de comunicação adotado por Benjamin e discutido por Sodré, ou seja, "se entendermos 'comunicar' como a ação de pôr em comum, por recursos simbólicos de mediação e vinculação, o que existencialmente não deve permanecer isolado (portanto, como uma partilha discursiva das possibilidades de compreensão)" (Idem, Ibidem: 180-181). Para evitar que o jornal também fique isolado devido ao desinteresse de seu público, é necessário deixar de lado a estrutura fixa que engessa histórias em torno de modelos pré-fabricados como o lead e a pirâmide invertida. Isso permite que a "força do relato" possa emergir do casulo da opaca objetividade para voar com o apoio de recursos próprios da literatura, como a reconstrução detalhada de cenas, os deslocamentos temporais da linha narrativa para criar suspense ou a participação subjetiva do repórter nos eventos relatados, de forma a "restituir o vívido da realidade" (Idem, Ibidem: 214).

Sodré analisa que os textos abstratos, repetitivos e desinteressantes do jornalismo deixaram com que a ficção se tornasse "socialmente mais pregnante" do que o relato e a análises de fatos. Uma saída apontada pelo autor seria o retorno das estratégias narrativas devido à força da dramatização, que "reequilibra os efeitos amnésicos típicos da mídia em seu modo de apresentação dos acontecimentos, cuja sucessão cada vez mais veloz leva-os a fagocitarem uns aos outros, perturbando a construção de um sentido na duração". Sodré prossegue: "Na dimensão dramática, movida a afeto, os atores sociais encontram balizas cruciais para a memória coletiva dos fatos" (Idem, Ibidem: 231).

Como o detetive dos romances policiais analisados no último capítulo do livro, os jornalistas precisam resolver mistérios a partir de pistas e apontar a identidade dos culpados para sua punição. Um enigma tão atual quanto urgente envolve a apatia do público pelas estruturas narrativas tradicionais da imprensa. A saída, como sugerido por Sodré, pode ser encontrada nas páginas dos romances noir: o detetive desenrola um novelo que encobre a identidade enigmática do criminoso ao mesmo tempo em que o autor envolve seu público no fio narrativo usado para destrinchar os acontecimentos. Cabe ao jornalista esse duplo papel - de detetive e narrador - para revelar fatos e envolver seu público; a partir de um relato intrigante, amarra-se, nas duas pontas, a informação bem apurada e um público fascinado pela forma como os fatos 
foram contados. Para isso, basta tecer um fio narrativo envolvente para unir ambas as pontas num laço.

\section{Bibliografia:}

SODRÉ, Muniz. A narração do fato: notas para uma teoria do acontecimento. Petrópolis: Vozes, 2009.

\section{Notas:}

(1) BENJAMIN, W. "O narrador - considerações sobre a obra de Nikolai Leskov". In: Obras escolhidas. Magia e técnica, arte e política. Vol. I. São Paulo: Brasiliense, 1985.

\section{Mini Currículo :}

Mestrando do Programa de Pós-Graduação em Ciências da Comunicação da ECA-USP, orientado pela Profa. Dra. Mayra Rodrigues Gomes, pesquisa a produção do correspondente americano Larry Rohter, do New York Times. 